\title{
FINANCIAMENTO DESCENTRALIZADO DA SAÚDE: A CONTRIBUIÇÃO DOS MUNICÍPIOS PAULISTAS
}

\author{
Áquilas Nogueira Mendes* \\ Suzana B. de Souza Santos**
}

\begin{abstract}
RESUMO: Nas discussões sobre o processo de implantação do Sistema Único de Saúde cada vez mais se evidencia a questão do seu financiamento. O processo de descentralização do SUS só pode ser concebido se forem considerados, de um lado, os recursos financeiros adequados ao governo municipal e, de outro, a própria gestão desses recursos, em termos de eficácia dos serviços. Nesta perspectiva, este trabalho, preocupado com a necessidade de informações constantes sobre o financiamento do SUS no Estado de São Paulo, criou um sistema permanente de coleta de dados "Sistema de Informação sobre o Financiamento de Saúde nos Municípios" -, para subsidiar o exercício dos gestores municipais; esse trabalho tem dados sobre as receitas e despesas municipais com saúde, nos períodos 1995/96/97. O "Sistema". registrou 442 municípios e possibilitou aos gestores de saúde o acesso a um instrumento que incorpora informações e relatórios importantes para os momentos de planjemento, acompanhamento, controle e avaliação dos recursos alocados em saúde.
\end{abstract}

PALAVRAS-CHAVE: Sistema Único de Saúde, financiamento da saúde, recursos financeiros, gestão dos recursos, municípios

* Doutorando em Economia pela UNICAMP, técnico do CEPAM e professor da Faculdade de Economia da FAAP ** Pós-graduanda em Economia pelo FIPE/FEA/USP, técnica do CEPAM e professora da Faculdade de Economia da FAAP. 


\section{INTRODUÇÁO}

Nos últimos anos, a maior participação de recursos municipais no gasto em saúde tem significado $o$ avanço do financiamento descentralizado desta área. Embora esse movimento não seja recente, em 1997 adquire patamares consideráveis, uma vez que os municípios paulistas destinam, em média $13,3 \%$ de suas principais receitas (impostos, transferências constitucionais - FPM e ICMS, etc.) para a saúde.

De um lado, esse quadro é decorrente da implementação do processo de descentralização do Sistema Único de Saúde - SUS que se inicia com a operacionalização da sua Norma Operacional Básica - NOB-01/93 e com a adoção do mecanismo de repasse Fundo a Fundo ${ }^{1}$. De outro lado, o compromisso desencadeado pelo processo de descentralização, obrigou muitos municípios a alocarem recursos próprios ${ }^{2}$ em saúde, principalmente após o (des)financiamento crescente dos recursos federais, agravado a partir de 1993.

O processo de (des)financiamento federal pode ser caracterizado em três fases: a que antecede a Constituição, o pós-Constituição e o pós-Real. Enquanto nos anos préConstituição (1980 a 1987) a saúde contava com recursos do Ministério da Previdência e o da Saúde, cerca de US $\$ 80$ / habitante/ano, no período pós-Constituição e, especialmente, na gestão Collor, estes recursos decresceram atingindo a marca de US $\$ 44 /$ habitante/ano em 1992 ${ }^{3}$. Elevar esse patamar aos padrões anteriores vem sendo a difícil tarefa desde 1993, quando o então Ministro da Previdência, Antonio Brito, deslocou grande parte dos recursos da saúde para sua Pasta. No período pós-Real, inicia-se um movimento de recomposição de valores, ainda que de forma gradual e tímida (CARVALHO \& MENDES \& MARQUES, 1998).

\footnotetext{
1 Essa Norma inaugura uma nova fase no processo de descentralização da saúde, pois ao criar tipos de gestão municipal incipiente, parcial e semiplena, cada uma delas tinha uma diretriz ancorada em responsabilidades a serem assumidas, requisitos a serem cumpridos e prerrogativas a serem usufruídas. Do ponto de vista dos recursos para esse processo de descentralização, foi criada uma nova sistemática dos fluxos de transferências de recursos, através do repasse Fundo a Fundo (Fundo Nacional de Saúde para o Fundo Municipal de Saúde), via decreto-federal de agosto de 1994. No Estado de São Paulo, esse novo mecanismo foi adotado em 50 municípios que assumiram a gestão semiplena municipal. Passaram a ser gestores de todos os recursos municipais, estaduais e federais dentro do município, desempenhando o papel de gestor único: executando, contratando, fiscalizando, controlando e avaliando. Aqui se realizou o novo processo de descentralização. A gestão parcial e incipiente, com adesão de mais duzentos municípios, não foi implantada efetivamente porque não pode usufruir as prerrogativas, ainda que tivessem cumprido requisitos e assumido responsabilidades.

2 Para efeito deste trabalho, gastos em saúde com "recursos próprios" são os realizados com recursos oriundos de receitas municipais, excluídas as transferências federais e estaduais vinculadas à área da Saúde.
}

3 Os gastos federais em saúde são extraídos da fonte IPEA/CSP e IESP/FUNDAP in Carvalho \& Mendes \& Marques (1998). 
Ao se acompanhar a evolução dos gastos federais com saúde, corrigidos pela média anual do IGP-DI de dezembro de 1998, percebe-se: em 1995, R\$18,7 bilhões, $R \$ 119,90 /$ habitante/ano; em 1996, R\$ 16,1 bilhões, $R \$ 102,55 /$ habitante/ano; em 1997, $R \$ 18,4$ bilhões, $\mathrm{R} \$ 115,00 /$ habitante/ano; e, em 1998, $\mathrm{R} \$ 19,0$ bilhões, $\mathrm{R} \$ 117,28 /$ habitante/ano (MENDES, 1999).

Em 1998, o gasto federal com saúde, excluídas as despesas com Inativos ( $R \$ 1,7$ bilhões) e a Dívida ( $R$ \$ 1,9 bilhões), oriunda do empréstimo de recursos do Fundo de Amparo ao Trabalhador, quando da retirada dos recursos efetuada pelo Ministro Brito, totaliza apenas $\mathrm{R} \$ 15,4$ bilhões, correspondendo a $\mathrm{R} \$ 95,00 /$ habitante/ano.

Sabe-se que a descentralização fiscal, consolidada pela Constituição de 1988, ao permitir a ampliação significativa de transferências de recursos e maior poder de arrecadação a estados e municípios, não estabeleceu um processo pactuado de redefinição de funções e competências de gestão na área social, em especial na saúde, capaz de estabelecer um conjunto, pelo menos, equivalente de atribuições a serem desempenhadas pela esfera municipal de governo, beneficiada pelo novo arranjo tributário.

Com base neste fato, há quem argumente que o governo federal, ao se encontrar fiscalmente debilitado, não adotou nenhuma iniciativa importante de reforma no seu esquema de financiamento. Isto é, os recursos federais, por se constituírem em uma fonte fundamental do SUS, deveriam, de um lado, ser ampliados quanto ao seu montante, e de outro, estar relacionados a uma proposta global de alocação, via transferência automática e não vinculada a programas estabelecidos, seguindo orientação claramente redistributiva, de acordo com critérios gerais de definição de prioridades e com um modelo de atenção à saúde, compatíveis com as necessidades da população.

Diante da inexistência de uma reforma do financiamento dessa natureza, o município passou a assumir mais tarefas na gestão dos serviços e ações de saúde, elevando de forma significativa o volume de recursos próprios aplicados à saúde e contribuindo para a lógica de um financiamento descentralizado, porém sem a esperada coordenação do nível central.

A Norma Operacional Básica do SUS mais recente - NOB/96, que avança na regulamentação do processo de descentralização, aprimorando sua gestão e direcionando para uma alteração no modelo de atenção à saúde, reafirma a importância do financiamento adequado, enquanto um dos instrumentos cruciais para a construção do sistema. Pela NOB96 o financiamento do SUS deve contar, na esfera estadual com os recursos advindos do Tesouro e dos transferidos pelo governo federal, e na municipal com recursos do seu tesouro 
e dos transferidos pelos governos federal e estadual ${ }^{4}$.

Face ao (des)financiamento do setor, por parte do governo federal, e também, pelo governo estadual, decorrente da baixa magnitude dos seus gastos com saúde 5 , é necessário atentar para a sua operacionalização, bem como para os instrumentos de planejamento, controle e avaliação dos recursos, por parte dos diferentes gestores do sistema, evidenciando a necessidade de uma maior racionalidade na alocação dos mesmos, tornando fundamental o acompanhamento das estruturas de receita e despesa da saúde, principalmente, nos municípios, responsáveis diretos pela execução dos serviços.

Para dar conta deste conjunto de preocupações, este trabalho analisa a extensão do gasto municipal com saúde nos municípios paulistas e suas fontes, tendo em vista evidenciar a contribuição dos recursos municipais no financiamento do sistema. Procura, também, identificar o gasto com saúde dos municípios que se habilitaram à condição de gestão semiplena do SUS, conforme a Norma Operacional Básica 01/93. Trata, portanto, de examinar se esses municípios vêm comprometendo maiores parcelas de seus recursos com a saúde local, uma vez que respondem por todos os serviços e ações nesta área.

\section{BASE EMPÍRICA DO FINANCIAMENTO DA SAÚDE NOS MUNICÍPIOS PAULISTAS}

A base empírica deste trabalho compreende os dados da pesquisa realizada pelo Cepam/Cosems/SES "Financiamento da Saúde nos Municípios Paulistas". O Cepam, preocupado com a necessidade de informações constantes sobre o financiamento do SUS no Estado de São Paulo, com vistas a subsidiar o exercício do papel dos gestores municipais, dado que é uma de suas principais atribuições prestar assessoria aos municípios, criou um sistema de informação permanente de coleta de dados - "Sistema de Informação sobre o Financiamento da Saúde nos Municípios (SIFSAM)". Este trabalho, inédito, que se iniciou por uma pesquisa, para depois vir a se constituir em um sistema, dispõe de dados sobre as

\footnotetext{
4 Esta NOB, do ponto de vista da sistemática de transferência de recursos, trouxe a grande novidade que foi o Piso de Atenção Básica - PAB, um valor per capita igual para todos os municípios com a responsabilidade de executar ou gerenciar as ações da atenção básica no município. Fica estabelecido aqui um mecanismo de repasse automático de recursos da esfera federal para a municipal, no que diz respeito a ações e serviços básicos de saúde.

5 Nos últimos anos, o gasto da Secretaria de Estado da Saúde de São Paulo - SES - com recursos do Tesouro foi de pequena participação em relação à despesa total do Governo do Estado. Registre-se: em 1995, R\$1,7 bilhões, sendo 4,6\% da despesa total do Estado ( $\mathrm{R} \$ 34,9$ bilhões); em 1996, R\$ 1,6 bilhões, 4,4\% da despesa total do Estado (R \$ 35,6 bilhões); e, em 1997, $\mathrm{R} \$ 1,7$ bilhões, $4,7 \%$ da despesa total do Estado ( $\mathrm{R} \$ 36,2$ bilhões) - Valores corrigidos pela média anual do IGP-DI de dezembro de 1998 (Pesquisa CEPAM/SES/COSEMS, 1998).
} 
receitas e despesas dos municípios em geral, e da saúde, em particular, relativas ao período 1995,1996 e $1997^{6}$.

\section{Amostra}

Foram pesquisados todos os municípios paulistas, ou seja 625 para os anos de 1995/96, e 645 para 1997. Como amostra geral para a pesquisa foi trabalhado um total de 431 municípios (69\%) nos anos de 1995 e 96, o que corresponde a, respectivamente, 77,8 e $77,7 \%$ da população do interior do Estado. Em 1997, a amostra foi ampliada, para 442 municípios, representando $69 \%$ do total dos municípios e $76,7 \%$ da população total do interior do Estado. Cabe registrar que a capital do Estado não se encontra na amostra pesquisada. Em termos de significância da amostra por porte populacional, registrou-se nos três anos pesquisados, uma média de: $65,5 \%$ na faixa de população até 10.000 habitantes; $66,7 \%$ na faixa de 10.001 a 20.000 habitantes; $72,5 \%$ na faixa de 20.001 a 50.000 habitantes; $75,6 \%$ na faixa de 50.001 a 100.000 habitantes e $76,3 \%$ com população acima de 100.000 habitantes.

Em termos de abrangência das semiplenas, a amostra responde por 39 municípios, correspondendo a $78 \%$ do total dos municípios enquadrados nesta condição de gestão do SUS, 50 até fevereiro de $1997^{7}$. Para efeito da análise das semiplenas, também, foram distribuídos os municípios, segundo a época de adesão. Parte-se do pressuposto que 0 reflexo dessa adesão ao SUS, tende a alterar a forma do seu gasto com saúde.

Quanto à época de adesão, as semiplenas estão distribuídas das seguinte forma:

60 "Sistema" foi montado em MS Excel e distribuído aos 645 municípios do Estado de São Paulo. É importante assinalar que, para além da riqueza das informações apuradas por esse levantamento, relativas à aplicação de recursos financeiros municipais do SUS/SP, a configuração e a disponibilidade de um Sistema aos Municípios, possibilitou aos gestores de saúde, o acesso a um conjunto de planilhas, relatórios e gráficos de análise financeira da receita e despesa do seu município e da área da saúde, em particular. Este instrumento incorpora informações e relatórios importantes para os momentos de planejamento, acompanhamento, controle e avaliação dos recursos alocados em saúde (CEPAM/COSEMS/SES, 1999).

$7 \mathrm{Na}$ realidade, após fevereiro de 1997, ocorreu uma paralização do processo de municipalização - nenhuma habilitação de municípios às condições de gestão da NOB-93 do SUS. Dados extraídos do banco de dados do Ministério da Saúde. 
QUADRO I - Distribuição dos municípios da amostra em semiplena, por época de adesão e porte populacional

\begin{tabular}{l|cccc|l}
\hline \multirow{2}{*}{ PORTE POPULACIONAL } & \multicolumn{4}{|c|}{ ÉPOCA DE ADESÃO } & \multirow{2}{*}{ TOTAL } \\
\cline { 2 - 5 } & 1994 & 1995 & 1996 & 1997 & \\
\hline Até 10.000 hab. & - & - & 3 & - & 3 \\
10.001 a 20.000 hab. & - & - & 4 & - & 4 \\
20.001 a 50.000 hab. & - & 1 & 9 & 1 & 11 \\
50.001 a 100.000 hab. & 3 & - & 5 & - & 8 \\
Maior que 100.000 hab. & 8 & 2 & 3 & - & 13 \\
\hline Total da Amostra & 11 & 3 & 24 & 1 & 39 \\
\hline
\end{tabular}

\section{Significado do Gasto Municipal com Saúde da Pesquisa}

Para efeito deste trabalho, foi realizado um levantamento do gasto municipal com saúde que se refere a todos os recursos financeiros que as prefeituras aplicam diretamente na área da saúde, tanto os arrecadados pelo próprio município, como também os obtidos através de transferências federais e estaduais vinculadas à esta área.

Para efeito de análise dos dados desta pesquisa não são considerados gastos municipais com Saúde aqueles que não transitam pelo orçamento municipal, tais como: a) os repasses financeiros do governo federal e estadual diretamente às instituições ligadas à saúde (ex: Santas Casas etc.); b) os repasses do governo federal e estadual realizados em espécie, como soro/vacinas, medicamentos e etc; e, c) os recursos do governo federal e estadual destinados ao pagamento de servidores cedidos aos municípios.

O presente trabalho emprega como deflator adequado a uma série de fontes e gastos em saúde o Índice Geral de Preços - Disponibilidade Interna (IGP/DI) da Fundação Getúlio Vargas, base agosto de 1994, corrigindo os valores nominais ou correntes de 1995, 1996 e 1997, para valores reais, a preços de dezembro de 1998. 


\section{GASTO COM SAÚDE DOS MUNICÍPIOS PAULISTAS}

Ao longo dos anos 1995 a 1997, registra-se um gasto médio per capita anual em saúde, incluindo as fontes federal, estadual e municipal da ordem de $R \$ 98,29 /$ habitante/ ano. Inicialmente, cabe, pelo menos, indagar: gasta-se muito ou pouco, em relação a quê? Sem dúvida, se o montante de gasto é confrontado com as necessidades da população, pode-se dizer que se tem gasto pouco, uma vez que nossos vizinhos latino-americanos gastaram, em média, US\$120.00/habitante/ano ${ }^{8}$ (dados de 1990).

No entanto, tomando os valores consolidados, por estrato populacional, depreendese que esse "pouco" não deve ser atribuído aos pequenos municípios - até 10.000 habitantes, que comparados às demais faixas populacionais, registraram os maiores e crescentes índices de gasto médio per capita com saúde. O comportamento desse gasto apresentou uma média anual per capita de R\$117,67, em 1995; R\$119,63, em 1996; e, R\$141,05, em 1997. Os demais municípios, pertencentes às outras faixas populacionais, inclusive os "maiores que 100.000 habitantes, não apresentaram, ao longo dos anos analisados, um gasto médio superior a $\mathrm{R} \$ 88,36 /$ habitante/ano.

Analisando-se os municípios que aderiram à gestão semiplena em 1994, para efeito de comparação durante os três anos deste trabalho, percebe-se através do Quadro 2, que tanto os 3 municípios na faixa de 50.000 a 100.000 habitantes, quanto aos 8 municípios com mais de 100.000 habitantes, apresentaram um gasto médio per capita em saúde bastante acima dos demais municípios da amostra.

QUADRO 2 - Gasto per capita médio em saúde por parte populacional - 1995/97

\begin{tabular}{lllllll} 
& & & & \multicolumn{3}{c}{ Em R\$ per capita/ano de Dez/98 } \\
& 1995 & & 1996 & & 1997 \\
Porte Populacional & Total Amostra & Semiplenas* & Total Amostra & Semiplenas* & Total Amostra & Semiplenas* \\
Até 10.000 hab. & 117,67 & - & 119,63 & - & 141,05 & - \\
10.001 a 20.000 hab. & 78,38 & - & 80,43 & - & 70,62 & - \\
20.000 a 50.000 hab. & 75,18 & - & 80,93 & - & 72,37 & - \\
50.001 a 100.000 hab. & 68,87 & 104,13 & 72,08 & 114,96 & 69,69 & 101,99 \\
Maior que 100.000 hab. & 79,91 & 128,63 & 88,36 & 157,70 & 87,16 & 148,91 \\
MÉDIA DA AMOSTRA & 94,17 & & 97,40 & & 102,31 &
\end{tabular}

Fonte: Banco de Dados CEPAM

Deflator: IGP-DI de Dez/98

* Referem-se aos 11 primeiros municípios que aderiram à condição de gestão semiplena.

8 Relatório do Banco Mundial - 1993. 
A situação demonstrada no quadro vem a comprovar que os primeiros que aderiram à semiplena, especialmente os 8 maiores municípios, por apresentarem uma situação de gestão financeira na área da saúde diferenciada, puderam obter ganhos consideráveis em relação aos demais municípios do seu porte. Na seqüência dos anos analisados, os ganhos registrados no gasto total per capita foram de $61,1 \%, 75,8 \%$ e $70,8 \%$, respectivamente.

Em 1997, cabe registrar que, à exceção dos pequenos municípios, em todas as faixas populacionais, inclusive nos semiplenas, houve uma retração do gasto médio per capita com saúde, em relação ao ano anterior. Este fato deve ser atribuído à redução da fonte recursos municipais, principal componente do financiamento da saúde nos municípios paulistas.

A redução da aplicação de recursos na saúde, decorre da instabilidade das finanças municipais, que se traduz pelo decréscimo da receita disponível (arrecadação de impostos mais transferências constitucionais - FPM e Quota-Parte do ICMS).

Cabe alertar que, a receita disponível per capita dos municípios paulistas, vem apresentando, em $53,2 \%$ deles, os maiores de 10.000 habitantes, uma pequena queda em termos reais, da ordem de $0,6 \%$ no período $1995 / 97$, variando de $R \$ 483,52$ para $R \$ 480,75$, respectivamente (MENDES \& SANTOS, 1999).

Nos pequenos municípios, a receita disponível per capita é $42,3 \%$ maior que a média dos municípios pesquisados, em decorrência do crescimento das transferências federais (12,3\% no período 1995/97), principal fonte de receita desses municípios. Em todos os estratos populacionais, a composição da receita disponivel vem apresentando um crescimento da participação das transferências federais e uma queda das estaduais.

Em termos da receita tributária, apenas os pequenos municípios obtiveram um modesto acréscimo entre 1995 e 1997, porém esta fonte de receita só é relevante para os maiores que $\mathbf{5 0 . 0 0 0}$ habitantes, especialmente para os municípios litorâneos e estâncias climáticas e hidrominerais, onde representa mais de $50 \%$ da receita disponível.

O fato da receita disponível estar diminuindo e a receita tributária dos municípios paulistas ser pouco expressiva, explica a redução do gasto médio per capita com saúde em 1997. Principalmente, porque a maior fonte de recursos deste gasto é oriunda dos recursos próprios dos municípios, numa média de $\mathrm{R} \$ 76,45$ /habitante/ano. 
RECURSOS PRÓPRIOS DOS MUNICÍPIOS: A PRINCIPAL FONTE DO GASTO EM SAÚDE

No período analisado, os recursos municipais respondem por $74,6 \%$ do gasto total com saúde. Registre-se: $R \$ 71,18$ em 1995, $R \$ 74,47$ em 1996, e $R \$ 77,70 /$ habitante/ano em 1997 (Gráfico 1). Ao longo desses anos, os recursos federais colaboraram, em média, com $R \$ 20,63 /$ habitante/ano, enquanto os recursos estaduais, com apenas $R \$ 3,21 /$ habitante/ ano.

Sem dúvida, o (des)financiamento da saúde, devido à escassez dos recursos federais e estaduais e à aceleração do processo de descentralização e municipalização do SUS, impuseram aos municípios paulistas, um maior direcionamento de recursos próprios para a área da saúde.

Ao se verificar a distribuição por porte populacional, percebe-se que há uma redução da fonte municipal, entre os anos de 1995 e 1997, à exceção dos municípios pequenos, menores que 10.000 habitantes (Gráfico 2). Estes, aumentaram seus gastos per capita/ano em saúde com recursos próprios, passando de $R \$ 91,83$, em 1995 , para $R \$ 95,35$, em 1996, e alcançando $R \$ 110,77$, em 1997. Desta forma, cabe assinalar que o processo de descentralização e municipalização da saúde tem exigido um esforço financeiro considerável dos municípios pequenos, uma vez que com a crise das finanças municipais, diferentemente dos demais portes, conseguiram manter um tendência de crescimento do seu gasto per capita.

Gráfico 1 - Gasto médio per capita em saúde, por fonte de recursos

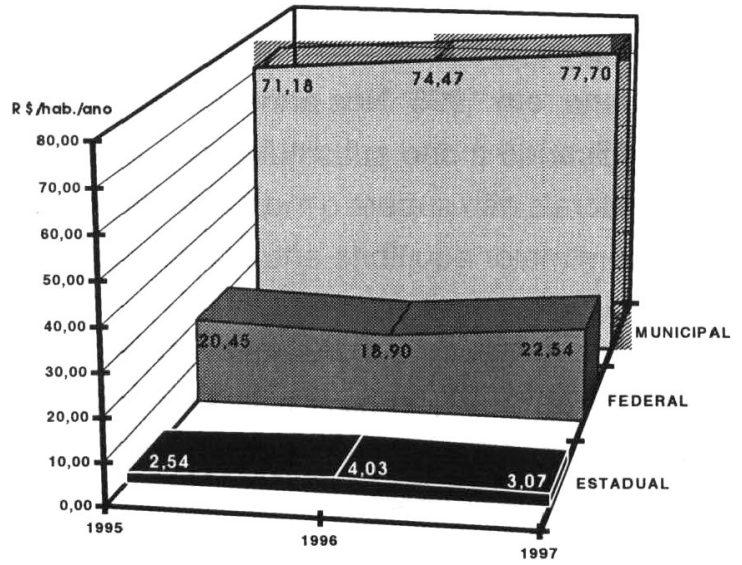


Gráfico 2 - Gasto Médio per capita em Saúde com Recursos Municipais

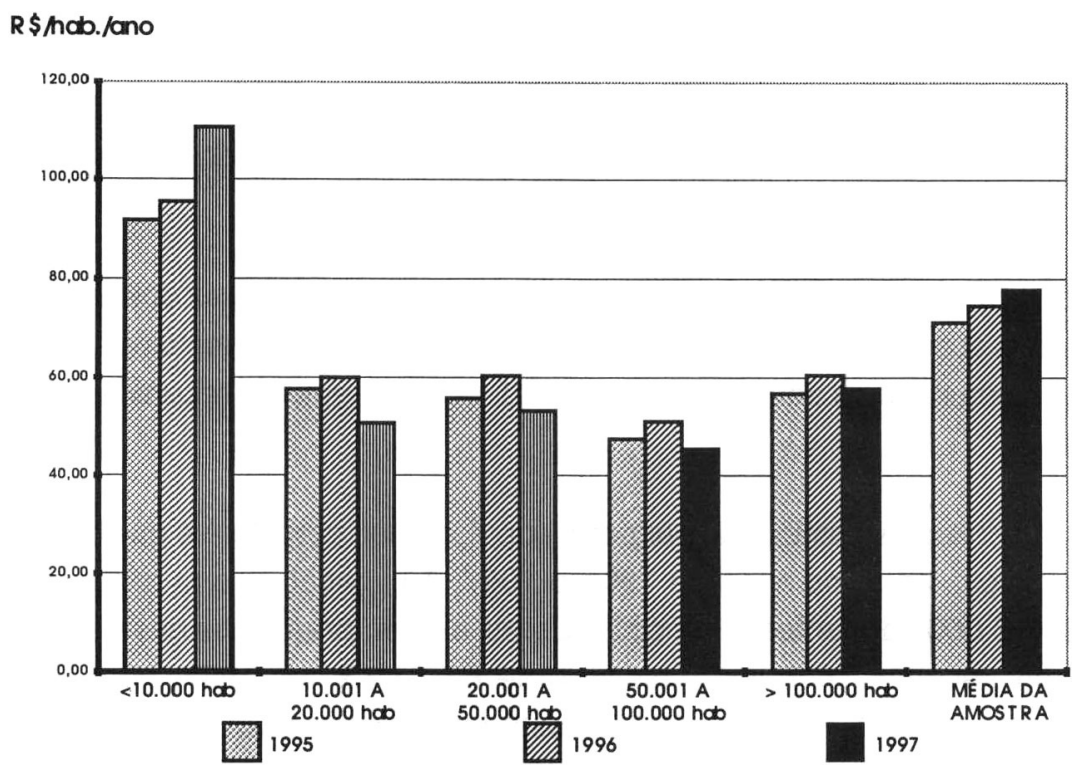

Fonte: Banco de Dados CEPAM Deflator: IGP-DI de Dez/98

Quanto aos três pequenos municípios que aderiram à gestão semiplena em 1996, percebe-se que, mesmo antes de sua adesão, já apresentavam uma aplicação de recursos próprios em saúde, $24,0 \%$ acima do padrão médio dos municípios de seu porte, destinando cerca de $R \$ 113,23$ habitante/ano, em 1995. Nos anos que se seguem, estes continuam a apresentar essa tendência, indicando a não substituição da fonte própria pela federal, ou seja, o ingresso de recursos federais não supera o montante de recursos próprios aplicados em saúde, porém promovem um maior equilíbrio entre essas duas fontes.

Nos grandes municípios, acima de 100.000 habitantes, tanto no total da amostra, como nos semiplenas, apesar de, em 1997, ter havido uma redução dos gastos com recursos municipais, esta se deu a um patamar superior ao verificado em 1995 (2\%) (Gráfico 2). Vale ressaltar que nesta faixa populacional concentra-se a maioria dos municípios paulistas em semiplena. 
No demais portes populacionais, o gasto per capita em saúde com recursos municipais registrou uma queda entre 1996 e 1997, ficando abaixo dos níveis alcançados em 1995.

Em 1997, dos 39 municípios em gestão semiplena pertencentes à amostra desta pesquisa, em 18 a fonte federal ultrapassa a municipal. Porém, há que se ressaltar que o diferencial entre as duas fontes é bastante pequeno. Nos 21 municípios onde predomina a aplicação de recursos municipais, nota-se que o processo de municipalização da saúde já vinha ocorrendo há mais tempo, anteriormente à sua habilitação ao SUS.

\section{PARTICIPAÇÃO DO GASTO EM SAÚDE, COM RECURSOS MUNICIPAIS, EM RELAÇÃO À DESPESA TOTAL DO MUNICÍPIO.}

O período em análise, aponta um constante crescimento da participação dos recursos municipais no gasto em saúde, em relação à despesa total do município. Em 1995, entre os municípios da amostra, registra-se uma média de 11,5\%; em 1996, 12,4\% e, em 1997, $13,1 \%$. Ao se verificar as diferentes faixas populacionais, depreende-se que esta tendência de crescimento é geral.

Contudo, é importante alertar que, embora os municípios tenham incrementado a participação dos recursos municipais em saúde em relação à despesa total, isto não significou uma ampliação em termos de gasto per capita/ano, que diminuiu de $\mathrm{R} \$ 74,47 \mathrm{em} 1996$, para $R \$ 77,70$ em 1997. Como já foi dito, esta retração foi devida à instabilidade das finanças municipais, que se traduziu pela redução da receita disponível (arrecadação própria mais transferências constitucionais).

\section{O predomínio das despesas correntes em saúde.}

No período analisado, há um predomínio das despesas correntes - custeio e transferências - $(95,6 \%)$, em relação às despesas de capital. - investimentos, inversões financeiras e transferências. Na realidade, os municípios, de maneira geral, apresentam baixo nível de investimento em saúde durante todo o período.

Cabe assinalar que o avanço do processo de municipalização da saúde no Estado, a partir de 1995, impôs aos municípios a necessidade de um considerável contingente de recursos humanos para a execução dos vários programas da área, além de uma garantia 
financeira para a manutenção das atividades. Sem dúvida, este quadro acarreta um incremento constante de seus gastos correntes, e especialmente, os relacionados à pessoal.

É preciso assinalar, ainda, que a maior parte dos estudos que analisa o desempenho dos gastos municipais, revela uma tendência de queda da despesa de capital (investimento) no primeiro ano de gestão das prefeituras. As razões para este fato, decorrem das particularidades do primeiro ano da nova administração - "manter o que vinha funcionando dos negócios públicos". Nessa pesquisa, os dados para 1997 confirmam este movimento de início de gestão municipal. Acrescente à isso, o fato de que os 22 novos municípios, todos de pequeno porte, tiveram a necessidade de montar seus quadros de pessoal, sendo que 11 integram a amostra.

Dentre as despesas correntes, como era de se esperar, é crescente a participação do gasto com pessoal, sendo responsável por mais da metade desses dispêndios. Isto vale tanto para os municípios em geral, como para as semiplenas (Gráfico 3).

É importante assinalar que, a exemplo do gasto geral da União e do Estado com saúde, verifica-se, também, no gasto municipal, um elevado grau de rigidez, ou seja, boa parte da receita disponível está previamente comprometida com o pagamento das despesas de difícil compressão - despesas com pessoal, incluindo encargos, acrescida dos inativos e pensionistas. Isto é, essas despesas são aquelas que por razões de ordem legal, os municípios tem dificuldade em restringir, ou seja efetuar $\operatorname{cortes}^{9}$.

Um outro item importante, refere-se às despesas com serviços de terceiros na área da saúde, o que nos permite ter uma visão mais acurada acerca do gasto com pessoal direto e indireto no setor. Tais despesas se mantêm num patamar médio de $17,2 \%$ do gasto total em saúde. No entanto, há que se mencionar que vários municípios vêm apresentando, ao longo do período de análise, um crescimento dessas despesas.

Em relação aos municípios em gestão semiplena, a participação dos gastos em pessoal e em serviços de terceiros em relação às despesas correntes, apresentam-se em patamares superiores aos demais municípios amostrados. Esta situação é perfeitamente explicável, uma vez que estes municípios ao assumirem a responsabilidade de todas as ações e serviços de saúde no seu território, ampliam não só seus gastos diretos com pessoal, mas também os decorrentes de convênios e contratos com entidades filantrópicas e do setor privado, respectivamente.

9 Vale lembrar que, no caso dos municípios, torna-se difícil a separação dos gastos com inativos e pensionistas originários da saúde, uma vez que, estes se encontram agregados na unidade orçamentária "Administração Geral". 
Gráfico 3 - Distribuição das despesas correntes em saúde
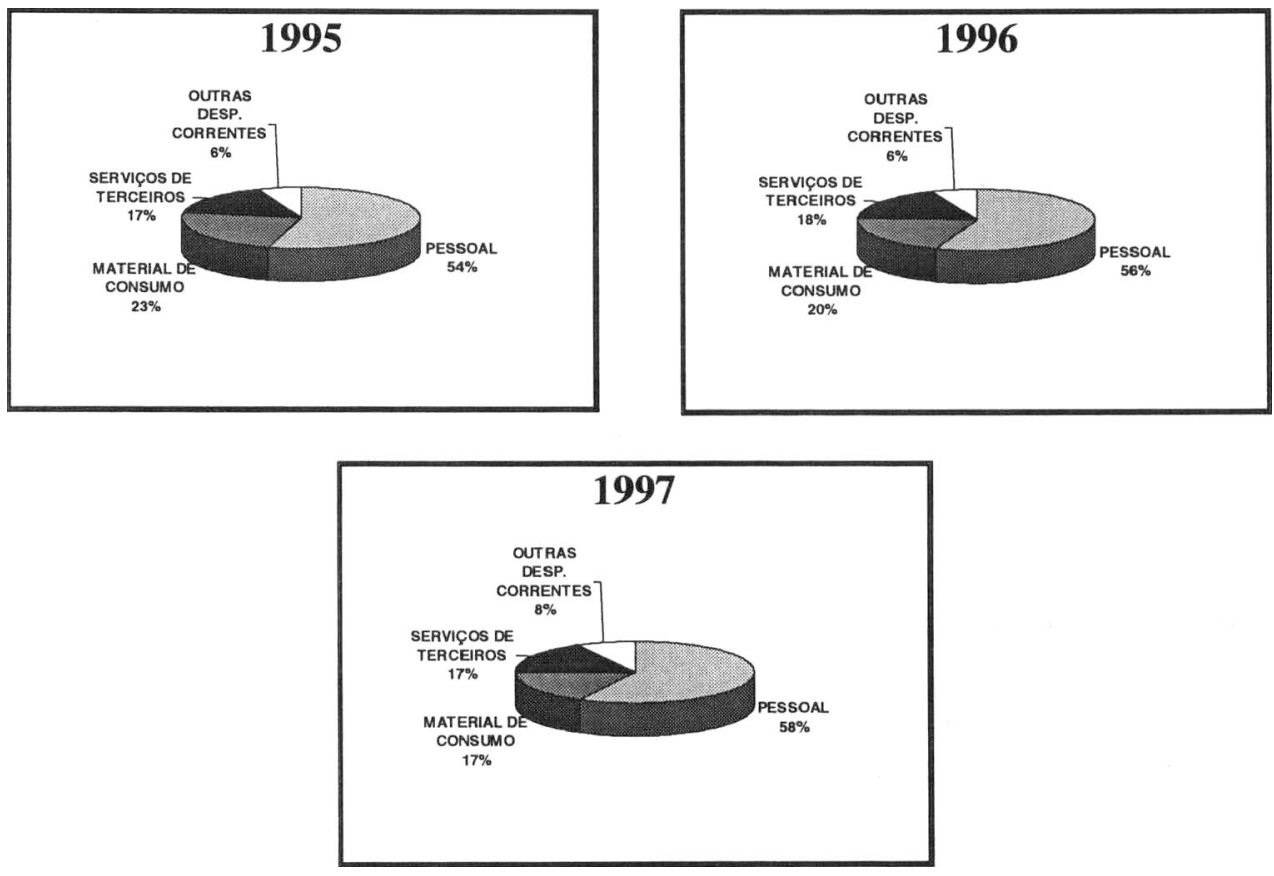

Fonte: Banco de Dados CEPAM

Deflator: IGP-DI de Dez/98

\section{CONSIDERAÇÕES FINAIS}

A gestão descentralizada do SUS ampliou os gastos em saúde nos municípios paulistas. $O$ que se pode identificar neste trabalho foi a manutenção e o alargamento da participação dos recursos municipais no financiamento do gasto local. Também, pode-se depreender um crescimento da fonte federal, que passa a se constituir, geralmente, em segundo plano, como uma fonte adicional de recursos do gasto local em saúde, principalmente nos habilitados em gestão semiplena.

É importante dizer que os municípios não podem prescindir da fonte federal do gasto em saúde, principalmente, no atual cenário econômico de ajuste fiscal. Ademais, cabe acrescentar que o (des)financiamento da saúde, por parte dos recursos federais precisa ser corrigido, devendo, também, os recursos estaduais, participarem de uma forma mais efetiva. 
O processo de descentralização do SUS vêm onerando de forma mais intensiva os orçamentos dos pequenos municípios, que em função da falta de escala de serviços, acabam por comprometer parcelas maiores dos seus orçamentos. Neste caso, se a reforma tributária for aprovada com base no conteúdo do projeto do relator Mussa Demes, os municípios irão perder receitas e, particularmente, os pequenos municípios, não terão condições de arcar com esse financiamento.

Como a descentralização da saúde é um instrumento para que se possa seguir um caminho mais eficiente e eficaz na construção do "Sus para todos", o comprometimento dos três níves de governo no financiamento do sistema, deve seguir a lógica eqüitativa, isto é, quem dispõe de mais recursos, deve colaborar com a maior parcela do financiamento, para que todos os cidadãos possam usufruir de melhores condições de saúde.

\section{REFERÊNCIAS BIBLIOGRÁFICAS}

CARVALHO, G. A Saúde no Brasil nas Fímbrias do $3^{\circ}$ Milênio: Tentando Analisar a Conjuntura, mimeo, junho de 1999.

CARVALHO, G. \& MENDES, A. N. \& MARQUES, R. O Financiamento do SUS: principios, série histórica e propostas. Apostila apresentada ao Curso de Capacitação para Gestores Municipais de Saúde. Secretaria de Estado da Saúde de São Paulo, Faculdade de Saúde Pública da USP e Conselho dos Secretários Municipais de Saúde de São Paulo, 1998.

CEPAM \& COSEMS \& SES Setor Público em Saúde: Gasto Estadual e Municipal. Relatório de Pesquisa. Projeto Receita e Despesa do Setor Público Municipal em Saúde no Estado de São Paulo e A Saúde no Contexto da Execução Orçamentária do Estado e o seu Financiamento com Recursos do Tesouro. outubro de 1998.

CEPAM \& COSEMS \& SES Financiamento da Saúde nos Municípios Paulistas: Gastos Municipais em Saúde e suas Fontes. Boletim no 1, março, 1999.

MENDES, A. N. Orçamento Municipal e Administração dos Recursos do Fundo Municipal de Saúde. Trabalho apresentado ao I Encontro de Prefeitos e Secretários Municipais do Estado de São Paulo - Saúde: Municipalização, Financiamento e Reforma Tributária. ANAIS. Indaiatuba, 6 de agosto de 1999.

MENDES, A. N.\& SANTOS, S.B. Cresce a Rigidez das Despesas dos Municípios Paulistas, mimeo, 1999. 


\section{HEALTH FINANCING IN THE MUNICIPALITIES OF THE STATE OF SÃo PAULO}

SUMMARY: During the discussions about the implementation process of the Unified Health System (SUS) the matter of financing has become explicit. The decentralization process of SUS can only be conceived only if we take into account, on one hand the financial resources adequate to the municipal government, and, on the other hand, management of these resources geared to service efficacy. In this perspective, and concerned with the need for constant information on financing of SUS in the State of São Paulo, this study developed a permanent data collection system - Information System for Health Financing in the Municipalities. The objective is to subsidize municipal management practices. Data were collected on municipal health income and expenditures in the period 1995-97. The System registered 442 municipalities and gave health managers access to a tool that incorporates information and reports important for planning, follow-up, control and assessment of resources allocated to health.

KEY WORDS: Unified Health System, health financing, financial resources, resource management, municipalities 